\title{
Asthma mortality: comparison between New Zealand and England
}

\author{
M R SEARS, H H REA, R P G ROTHWELL, T V O'DONNELL, P E HOLST, \\ A J D GILLIES, R BEAGLEHOLE
}

\begin{abstract}
Causes for the high mortality from asthma in New Zealand were investigated by comparing deaths from asthma in caucasian subjects aged 15-64 in New Zealand with those from asthma in the same age group in two regions in England. There were no significant differences in the accuracy of death certification. The verified asthma mortality in New Zealand $(4 \cdot 2 / 100000)$ was over twice that in England. Many characteristics of patients and management, including poor compliance with treatment and deficiencies in long term and emergency care, were qualitatively similar in the two countries. New Zealand had an apparently higher rate of non-preventable deaths from asthma, suggesting a greater severity of asthma in New Zealand. In both countries, however, most deaths were associated with poor assessment, underestimation of severity and inappropriate treatment (overreliance on bronchodilators and underuse of systemic corticosteroids), and delays in obtaining help. A greater frequency of some of these deficiencies in management remains a possible additional explanation for part of the excess mortality in New Zealand.
\end{abstract}

\section{Introduction}

There is now no doubt that New Zealand experienced an increase in asthma mortality in the late 1970 s, especially in the 5-34 year age group, whose mortality from asthma rose abruptly from $1977 .{ }^{1}$ Hospital admission rates for asthma increased, ${ }^{2}$ and while sales of antiasthma drugs also increased in the United Kingdom and Australia between 1975 and 1981, sales per head were highest in New Zealand. ${ }^{3}$ There was concern that changing patterns of drug treatment, particularly the combination of oral theophylline with $\beta$ sympathomimetic drugs ${ }^{4}$ and the use of home nebulisers for administration of high doses of $\beta$ sympathomimetics, ${ }^{5}$ might have influenced mortality. Alternatively, other aspects of management or characteristics of asthma in New Zealand may have changed.

In 1979 the British Thoracic Association surveyed asthma mortality in 15-64 year olds in two regions of England. ${ }^{6}$ From

University of Otago Medical School, Dunedin, New Zealand

M R SEARS, MB, FRACP, senior lecturer, department of medicine

Green Lane Hospital, Auckland, New Zealand

H H REA, MD, FRACP, respiratory physician

Waikato Hospital, Hamilton, New Zealand

R P G ROTHWELL, MB, FRACP, respiratory physician

Wellington Clinical School of Medicine, Wellington, New Zealand

T V O'DONNELL, MD, FRACP, professor, department of medicine

PE HOLST, MB, FRACP, associate professor, department of medicine

Princess Margaret Hospital, Christchurch, New Zealand

A J D GILLIES, MB, FRACP, respiratory physician

Department of Community Health and General Practice, University of Auckland, New Zealand

R BEAGLEHOLE, MD, FRACP, associate professor

Correspondence to: Dr M R Sears, Department of Medicine, University of Otago Medical School, PO Box 913, Dunedin, New Zealand.
August 1981 to July 1983 a two year nationwide study of asthma mortality was conducted in New Zealand. ${ }^{7}$ While New Zealand and the United Kingdom are not fully comparable in climate, population, ethnic mix, or organisation of health services, underlying similarities in the caucasian populations justify comparison of mortality from asthma between the two countries. It was hoped that such a comparison might suggest possible reasons for the much higher reported asthma mortality in New Zealand.

\section{Methods}

The Asthma Task Force of the Medical Research Council of New Zealand undertook a two year national review of all deaths in people usually resident in New Zealand who died between 1 August 1981 and 31 July 1983 and for whom part I of the death certificate or the coroner's report contained the word "asthma," "asthmatic," or "asthmaticus." Cases were identified by reviews of death certificates at local offices of registrars of births, deaths, and marriages and at the National Registry of Births, Deaths, and Marriages. After separate interviews with a close relative or friend and the general practitioner by a trained nurse interviewer, review of hospital records, and study of necropsy findings where available a panel of respiratory physicians determined whether the patient had suffered from asthma and whether the patient had died from asthma or its complications or treatment. ${ }^{8}$ If so, the panel reviewed the characteristics of the patient, the long term care, particularly over the year before death, the circumstances of the fatal episode, and the possibilities for intervention which might have prevented a fatal outcome.

After completion of data collection two of us had discussions with a member of the asthma mortality subcommittee of the British Thoracic Association, and subsequently one reviewed 15 representative New Zealand cases with two members of the subcommittee, who did not know the assessments of the New Zealand panel, to determine comparability of judgments regarding adequacy of management and preventability of death.

\section{Results}

\section{DEMOGRAPHIC DATA}

The verified mortality from asthma in 15-64 year olds of all races in New Zealand was 5.6/100000 compared with $1 \cdot 84 / 100000$ in England. ${ }^{6}$ As reported, ${ }^{7}$ death rates for asthma in the Maori and Pacific Island Polynesian populations were respectively $5.5(p<0.01)$ and $2.8(p<0.05)$ times higher than the rate for caucasians these higher rates accounted for $36 \%$ of the "excess" of the total New Zealand asthma mortality. The verified mortality in New Zealand caucasians aged $15-64$ was $4 \cdot 2$ per 100000 (table I), still more than twice that reported in England. The net accuracy of statistical coding of all cases studied did not differ significantly between the two countries. ${ }^{89}$

\section{CHARACTERISTICS OF PATIENTS AND THEIR ASTHMA}

The age and sex distribution of the subjects who died was similar in the two countries (table II). There were no significant differences in the ages at onset or durations of asthma; in both countries about $80 \%$ of patients had had asthma for over 10 years. One third of patients dying of asthma in England had been free of symptoms for periods of three months or more in the year before death, but this was rare in New Zealand patients, only $6 \%$ of whom had mild asthma not requiring emergency visits to a general practitioner or hospital in the year before death. In England 39\% of patients had had previous, sudden severe attacks, while in New Zealand $29 \%$ of patients had had life threatening episodes of asthma resulting in altered consciousness or documented hypercapnia. In one in 10 fatal cases in New 
TABLE I-Comparison of entry criteria, verified mortality rates, and accuracy of ICD coding of deaths from asthma in 15-64 year old caucasian subjects in New Zealand and England

\begin{tabular}{|c|c|c|}
\hline & New Zealand & England \\
\hline $\begin{array}{l}\text { Study period } \\
\text { Referral criteria }\end{array}$ & $\begin{array}{c}\text { August } 1981 \text { to July } 1983 \\
\text { "Asthma" or derivative in part I of death certificate or on } \\
\text { coroner's report }\end{array}$ & $\begin{array}{l}\text { January to December } 1979 \\
\text { "Asthma" anywhere on death certificate }\end{array}$ \\
\hline $\begin{array}{l}\text { Cases studied } \\
\text { Population at risk }\end{array}$ & $\begin{array}{c}185^{\star} \\
1750000\end{array}$ & $\begin{array}{c}153 \\
4890000\end{array}$ \\
\hline $\begin{array}{l}\text { Deaths coded to asthma by National Health Statistics Centre (New Zealand) or Office of } \\
\text { Population Censuses and Surveys } \\
\text { Verified deaths from asthma } \\
\text { Yearly verified asthma mortality per } 100000 \\
\text { Net accuracy of ICD coding of all cases }\end{array}$ & $\begin{array}{l}172 \\
147(85 \% \text { of coded deaths }) \\
4 \cdot 20 \\
81 \%\end{array}$ & $\begin{array}{c}101 \\
90(89 \% \text { of coded deaths }) \\
1 \cdot 84 \\
76 \%\end{array}$ \\
\hline
\end{tabular}

ॠThese data differ from those of New Zealand national asthma mortality study, ${ }^{7}$ which included non-whites and an age range of greater than $15-64$.

TABLE II-Characteristics of patients and their asthma. Figures are numbers (percentages) of patients

\begin{tabular}{lrr}
\hline & $\begin{array}{r}\text { New Zealand } \\
(\mathbf{n}=147)\end{array}$ & $\begin{array}{c}\text { England } \\
(\mathbf{n}=90)\end{array}$ \\
\hline Male & $74(50)$ & $41(46)$ \\
Age below 45 & $55(37)$ & $38(42)$ \\
Duration of asthma over 10 years & $116(79)$ & $72(80)$ \\
Symptom free for over three months in year before death & $9(6)$ & $30(33)$ \\
Chronic asthma & $138(94)$ & $60(67)$ \\
Reversible airflow obstruction & $77 / 85(91)$ & $22 / 27(81)$ \\
Atopic (by history or skin tests) & $105(71)$ & $52(58)$ \\
Previous severe attacks & $42(29)$ & $35(39)$ \\
Admitted to hospital: & $100(68)$ & $58(64)$ \\
At any time & $54(37)$ & $19(21)$ \\
In year before death & $14(10)$ & $3(3)$ \\
Previous mechanical ventilation & & \\
\hline
\end{tabular}

^Described as sudden, severe attacks in England: defined as life threatening attacks with altered consciousness or documented hypercapnia in New Zealand.

Zealand the patient had previously been ventilated for life threatening asthma. Proportionately more patients in New Zealand than in England had been admitted to hospital for asthma in the year before death. In both countries most of the patients who died were atopic and most of those tested had reversible airflow obstruction

\section{MANAGEMENT AND ASSESSMENT OF ASTHMA}

Patient compliance with treatment as judged by the reviewing panel was unsatisfactory in more than half of the patients in both countries, though general practitioners rated compliance as better in many cases (table III). A

TABLE III-Patient compliance and functional assessment. Figures are numbers (percentages) of patients

\begin{tabular}{lcc}
\hline & $\begin{array}{c}\text { New Zealand } \\
(\mathrm{n}=147)\end{array}$ & $\begin{array}{c}\text { England } \\
(\mathrm{n}=90)\end{array}$ \\
\hline Patient fully cooperative: & & \\
$\quad$ General practitioner assessment & $95(65)$ & $62(69)$ \\
$\quad$ Panel assessment & $54(37)$ & $42(47)$ \\
Unreliable in drug taking & $53(36)$ & $23(26)$ \\
Reluctant to seek medical help & $54(37)$ & $26(29)$ \\
Smokers: & $31(21)$ & $22(24)$ \\
$\quad$ Current & $49(33)$ & $19(21)$ \\
$\quad$ Past & $26(18)$ & $19(21)$ \\
Recent or frequent change of general practitioner & $85(58)$ & $27(30)$ \\
Lung function tests performed & $31(21)$ & $4(4)$ \\
Serial peak flow readings & & \\
\hline
\end{tabular}

somewhat greater proportion of New Zealand patients were considered unreliable in taking medications and reluctant to seek help. Lung function tests were more often available for New Zealand patients, though less than a quarter had used peak flow meters; considerably fewer patients in England had used peak flow meters. One in five patients in each country had had frequent or recent changes of general practitioner with consequent interruption of primary medical care.

\section{DRUG TREATMENT}

Comparatively more New Zealand patients with fatal asthma had used theophylline, inhalational corticosteroid, and nebulised bronchodilator but systemic corticosteroids were less frequently used than in England (table IV). Treatment as prescribed by the general practitioner comprised

TABLE IV-Regular drug treatment prescribed for 15-64 year old caucasian subjects who died of asthma in New Zealand and England. Figures are numbers (percentages) of patients

\begin{tabular}{lrc}
\hline & $\begin{array}{c}\text { New Zealand } \\
(\mathrm{n}=147)\end{array}$ & $\begin{array}{c}\text { England } \\
(\mathrm{n}=90)\end{array}$ \\
\hline BAgonist (oral or inhaled) & $144(98)$ & $85(94)$ \\
Theophylline & $93(63)$ & $37(41)$ \\
Ipratropium bromide & $29(20)$ & $\star$ \\
Cromoglycate & $22(15)$ & $\star$ \\
Inhalational corticosteroid & $77(52)$ & $30(33)$ \\
Systemic corticosteroids (daily or short courses) & $56(38)$ & $55(61)$ \\
Bronchodilators only & $40(27)$ & $25(28)$ \\
Domiciliary nebuliser & $37(25)$ & 0 \\
\hline
\end{tabular}

$\star$ Data not given.

both bronchodilator and anti-inflammatory agents in $49 \%$ of cases, but in many of these patients the dosages may have been inadequate, as lung function was not assessed. A home nebuliser was used by a quarter of the New Zealand patients for occasional or regular administration of a $\beta$ sympathomimetic, but many patients, including more than half of those with previous life threatening attacks, did not have access to oxygen or to a nebuliser. In England no patient dying of asthma had a home nebuliser. In both countries few relatives seemed to have a clear grasp of how to identify and manage severe attacks ("crisis plan").

\section{CIRCUMSTANCES OF FATAL ATTACK}

In both New Zealand and England the duration of the final attack varied between minutes and several days; in a quarter of cases the patient died in less than one hour from the apparent onset of the attack (table V). In New Zealand $31 \%$ of patients were known to have died within three hours of the apparent onset; a further $19 \%$ probably died in under three hours, but as they were found dead the time of death was less certain. Similar proportions of patients died at weekends and at night in the two countries. Fewer than half of all patients called their general practitioner or a deputy medical service. Only one fifth of patients in New Zealand called an ambulance compared with $38 \%$ in England; possibly as a result $14 \%$ died en route to medical care, mostly in private cars. Important delays in seeking medical help were evident in $37 \%$ of New Zealand cases, whereas in England 54\% of patients were considered to have delayed or failed to call help.

We found no evidence in caucasian New Zealand patients of excess theophylline usage in the fatal attack, and only five patients appeared to have used $a \beta$ agonist in doses exceeding those used regularly in hospital inpatients with acute severe asthma-namely, nebulisation of salbutamol or fenoterol $2 \cdot 5-5 \cdot 0 \mathrm{mg}$ every two hours. Cardiac arrhythmia due to drugs in the presence of hypoxia might explain the very few extremely sudden deaths, but we have no evidence for or against this hypothesis. As in England, however, there was evidence of underusage of systemic corticosteroids, both during the period of gradual deterioration leading to the final attack and at the time of 
medical intervention ( $46 \%$ of those treated during the attack were given little or no corticosteroid). In New Zealand 50 patients (34\%) had had a recent attack which was poorly assessed or poorly treated and $18(12 \%)$ had recently stopped or rapidly reduced their dose of oral steroids. Four patients were taking $\beta$ adrenergic blocking drugs, which in three contributed directly to death. There were no deaths after ingestion of aspirin or non-steroidal anti-inflammatory drugs. Twenty patients used antianxiety or antipsychotic drugs. Sedatives were given in only one of the fatal asthmatic attacks studied.

TABLE V-Events of fatal attack. Figures are numbers (percentages) of patients

\begin{tabular}{lcc}
\hline & $\begin{array}{c}\text { New Zealand } \\
(\mathbf{n}=147)\end{array}$ & $\begin{array}{c}\text { England } \\
(\mathbf{n}=90)\end{array}$ \\
\hline $\begin{array}{l}\text { Time of deatht: } \\
\text { Weekdays (Mon-Fri 0800-2000) }\end{array}$ & $31(21)$ & $16(18)$ \\
Weeknights (Mon-Fri 2000-0800) & $54(37)$ & $22(24)$ \\
Weekends (Fri 2000 to Mon 0800) & $58(39)$ & $37(41)$ \\
Duration of fatal attack: & $34(23)$ & $23(26)$ \\
<1 h & $12(8)$ & $10(11)$ \\
1-3 h & & \\
Help called: & $66(45)$ & $41(46)$ \\
General practitioner & $31(21)$ & $34(38)$ \\
Ambulance & $32(22)$ & $15(17)$ \\
Help received: & $7(5)$ & $\star$ \\
General practitioner & $55(37)$ & $49(54)$ \\
Ambulance & $38(26)$ & $25(28)$ \\
Delay in seeking help & $49(33)$ & $29(32)$ \\
Delay in medical response & $28(19)$ & $13(14)$ \\
Inadequate medical emergency care & $19(13)$ & $13(14)$ \\
Patient found dead & & \\
Death in hospital & & \\
\end{tabular}

$\star$ Data not given

+Unknown for 4 (3\%) cases in New Zealand; not stated for 15 (17\%) cases in England.

$\ddagger$ Failure to assess severity, begin steroids, or admit urgently.

\section{PREVENTABLE DEATHS}

The subcommittee of the British Thoracic Association determined that $86 \%$ of the deaths from asthma in England were associated with factors whose avoidance might have led to a different outcome (table VI). A similar

TABLE VI- "Avoidable" and "unavoidable" asthma mortality in New Zealand and England

\begin{tabular}{lcc}
\hline & $\begin{array}{c}\text { New Zealand 1981-3 } \\
(\mathrm{n}=147)\end{array}$ & $\begin{array}{c}\text { England 1979 } \\
(\mathrm{n}=90)\end{array}$ \\
\hline Verified asthma mortality & $4 \cdot 20$ & 1.84 \\
Avoidable deaths (No (\%)) & $98(67)$ & $77(86)$ \\
Avoidable deaths (rate) & $2 \cdot 83$ & 1.57 \\
Doubtfully avoidable (No (\%)) & $9(6)$ & $3(3)$ \\
Unavoidable deaths (No (\%)) & $40(27)$ & $10(11)$ \\
Unavoidable deaths (rate) & $1 \cdot 14$ & 0.20 \\
& & \\
\hline
\end{tabular}

*All rates are deaths/100 000/year.

judgment was made for $67 \%$ of the deaths in caucasian patients of the same age group in New Zealand. Discussions with two members of the British Thoracic Association's subcommittee and detailed review of the circumstances of 15 representative New Zealand cases by the two British Thoracic Association physicians who were unaware of the assessments made by the New Zealand panel assured us that, so far as was possible, these judgments were based on similar criteria in each country. The most common problem associated with an "avoidable" death in New Zealand was underassessment of severity of chronic asthma before the onset of the fatal attack ( $37 \%$ of all cases). Twelve patients recently given oral corticosteroids were not followed up by a doctor or tested for lung function, nor did they begin treatment with inhalational steroids. In 26 cases there was opportunity to give or increase oral corticosteroids during the early stages of the fatal episode but this was not done; instead antibiotics were often prescribed. Delays in attendance or in instituting appropriate treatment by doctors or ambulances were identified; in one instance a hospital clinic gave poor advice leading to delay. On the other hand, $37 \%$ of all patients delayed seeking medical help when their usual treatment was unavailable or ineffective. Treatment in hospital was inadequate in eight cases because of delay in the accident and emergency department, inadequate assessment, or inadequate corticosteroid treatment.

Given all the circumstances, $40(27 \%)$ of the deaths in New Zealand were considered by the panel to have been "unavoidable" compared with $10(11 \%)$ in England. In 27 cases (18\%) the patient apparently suffered a precipitous attack despite good long term management, while in five asthma worsened abruptly despite initiation of appropriate treatment. Four patients were found dead, having apparently been well shortly beforehand. Four died in hospital of irreversible end stage disease despite intensive treatment.

Eight deaths in the New Zealand series have not been included here. Five patients rarely if ever sought medical help unless in extremis or were totally non-compliant with advice given. In two deaths the circumstances were such that we were unable to determine whether death might have been avoided, and in one case the circumstances of death could not be ascertained.

\section{Discussion}

National statistics show that for several years the mortality from asthma has been substantially higher in New Zealand than in England and Wales and many other countries. This has been verified by two recent studies in New Zealand and England. ${ }^{67}$ In this comparison of mortality between countries we were unable to eliminate all potential bias in collection, analysis, and interpretation of data but attempted to minimise this by ongoing consultations among investigators. The two to three year interval between the studies may have accounted for some of the differences in drug treatment, particularly the use of nebulisers, as discussed more fully elsewhere.$^{10}$ In the regional study in England all interviews were conducted by one physician, whereas for logistic reasons interviews in the nationwide New Zealand study were conducted by six trained nurses; in both countries interviews were followed by careful review by a medical panel. Retrospective comparison of the independently developed questionnaires showed a close similarity; the few differences are explained above. Bias in subjective interpretation of adequacy and appropriateness of long term and short term care based on recall by relatives and medical records is less easily determined. Nevertheless, from our consultations and the review of representative New Zealand cases by two members of the British Thoracic Association's subcommittee we believe that such differences were small and not systematic. Racial and cultural differences between countries may be another source of bias. We excluded cases in Maoris and Pacific Island Polynesians from the comparison; the remaining caucasian population was genetically and culturally closely related to the caucasian population of the United Kingdom.

The national asthma mortality study has shown that the higher reported rates in New Zealand compared with England were not due to a greater proportion of errors of certification or coding.$^{89} \mathrm{The}$ methods of case review in each country excluded any effect from the introduction of the ninth revision of the International Classification of Diseases in 1979." The verified mortality of $4 \cdot 2 / 100000 \mathrm{New}$ Zealand caucasians aged 15-64 confirmed the New Zealand mortality from asthma in 1981-3 to be more than twice that of England in 1979. Had the study by the British Thoracic Association been contemporaneous with the New Zealand study this difference might have been slightly less, as asthma mortality is increasing slowly in England and Wales, ${ }^{12}$ but this change with time is small compared with the substantial difference between the two countries.

If data from the two regions studied in England are applicable nationally, and if the judgments made about whether or not deaths were preventable were comparable between countries, then the rate for "unavoidable" mortality from asthma was considerably greater in New Zealand than in the United Kingdom (table VI). Without both groups undertaking an independent review of all cases studied in both countries we cannot be certain that the same judgments would be made on all cases, but the two members of the British Thoracic Association's subcommittee who reviewed 15 representative New Zealand cases without knowledge of the New Zealand panel's assessment made identical judgments on which deaths were associated with "avoidable" factors. These factors included underassessment of severity of chronic asthma resulting in inadequate long term care, poor patient compliance with treatment (often 
associated with psychological problems and smoking), poor use of primary medical care, delay in calling for help in circumstances of increasing asthma, and underassessment of severity and inappropriate treatment of the acute attack.

Identified inadequacies in the long term management of patients with severe asthma in New Zealand were similar to those reported in England ${ }^{6}{ }^{1314}$ Probably many of the patients who died of asthma had poorly recognised chronic airflow limitation which could have been reversed or improved with more aggressive treatment, including oral corticosteroids.

Reluctance to initiate or increase steroid treatment for acute attacks and failure to monitor response to such treatment when it was used were common. An arbitrary five or seven day course of prednisone without subsequent clinical and functional review of the patient is dangerous: it may fail fully to reverse the airflow obstruction and may leave the patient susceptible to a further exacerbation of asthma as treatment is withdrawn. Instead, prednisone $30-60 \mathrm{mg}$ daily should be maintained for up to two weeks, until the peak expiratory flow returns to normal (or to the patient's known maximum) and there is minimal diurnal variation. ${ }^{\text {is }}$ When the prednisone dose is reduced peak flow measurements should be continued as well as clinical review and dose reduction halted if there is deterioration. Failure to initiate or increase inhalational steroids during withdrawal of oral steroids was another common error in management of the fatal cases in New Zealand.

The subcommittee of the British Thoracic Association recommended nebulised bronchodilator treatment as probably the best emergency treatment for acute asthma. ${ }^{6}$ In that study no patient had used a home nebuliser during the fatal attack. In New Zealand, perhaps because the study was undertaken two years later, and possibly because of a greater severity of asthma, nebulisers were prescribed for a quarter of those who died. In at least 12 instances over-reliance on a nebuliser led to a delay in seeking medical help or initiating other action. ${ }^{10}$ Grant was concerned about the high prevalence of use of nebulisers in New Zealand, particularly without peak flow monitoring or availability of oxygen. ${ }^{5}$ We emphasise the need for careful patient education in the use of nebulisers and the need for peak flow monitoring and an effective crisis plan for all patients requiring this form of treatment. As reported elsewhere, however, we believe that misuse of nebulisers at home contributed only slightly to asthma mortality in New Zealand. ${ }^{10}$

We found no direct evidence for bronchodilator drug toxicity, with no documented arrhythmias in patients admitted to hospital and no excessive theophylline doses or raised serum theophylline concentrations. Nor did we find that emergency management, when given, was hampered by the inability to use parenteral aminophylline in patients taking oral sustained release theophylline, which was prescribed more frequently in New Zealand than in England. The greatest increase in mortality in younger patients occurred three years before the abrupt increase in sales of antiasthma drugs, ${ }^{3}$ making an association between increased treatment and mortality unlikely. While the descriptive nature of this study does not allow us categorically to negate suggestions of toxic drug interaction, ${ }^{4}$ inadequate systemic corticosteroid treatment seemed a more likely explanation for part of the higher mortality in New Zealand. Patients dying of asthma in New Zealand were more frequently prescribed theophylline and inhalational corticosteroids than those dying in England, but oral steroids were less frequently used. Whether this pattern of drug usage applies to the treatment of asthma generally in each country is unknown.

Two further differences between New Zealand and England which may have affected management and hence mortality deserve comment. The fee that New Zealand patients pay for each consultation with a general practitioner may have been a disincentive to regular medical care and to seeking help in the early stages of a severe attack; however, this was rarely commented on in interviews. Similarly, though access to health care may be somewhat less immediate in parts of New Zealand than in the regions studied in England, remoteness from care was a factor in only $7 \%$ of all deaths. Deaths were not classified as unavoidable simply on the basis of remoteness from care.

The fall in asthma mortality in New Zealand in 1983, when our study ended, may have reflected an increased awareness of asthma mortality both within the profession and among the public with consequent improved management. Nevertheless, we remain concerned about the higher mortality compared with other countries. This is not an artefact of certification and may not be fully explained by the identifiable defects of management. The apparently higher rate of "unavoidable" deaths in New Zealand suggests that there are other factors which must be considered, including a change in severity of asthma. The anecdotal experience of immigrant physicians treating asthma in different countries, ${ }^{16}$ the increased prevalence and severity of asthma in Tokelauan immigrants to New Zealand, ${ }^{17}$ the sharp increase in use of antiasthma drugs in New Zealand, ${ }^{3}$ and this comparison of the New Zealand and English studies of asthma mortality suggest that as yet unknown environmental factors may have had an adverse effect on asthma mortality in New Zealand. On the other hand, this study does provide evidence for quantitative differences between New Zealand and England in some aspects of management of asthma, including drug use and patient willingness to present for medical care and review. We must leave open the possibility that these differences might account for at least part of the excess New Zealand mortality from asthma.

This work was supported by the Medical Research Council of New Zealand, the Maurice and Phyllis Paykel Trust, the New Zealand Asthma Society, and regional asthma societies. We acknowledge the excellent work of the interviewers Mesdames E Bollard, F Clark, J Fenwick, A Fullerton, V McClellan, and A Wilkie and express appreciation to relatives of the deceased, general practitioners, and hospital medical staff for their willingness to participate. The cooperation of the registrars of births, deaths, and marriages throughout New Zealand, the Department of Justice, hospitals, and pathologists is acknowledged, along with help given by the director and staff of the National Health Statistics Centre, Department of Health, Wellington. Statistical analyses were undertaken by Mr Alistair Stewart, department of community health and general practice, University of Auckland Medical School. The helpful continuing cooperation of members of the British Thoracic Association Asthma Deaths Subcommittee is acknowledged.

\section{References}

1 Jackson RT, Beaglehole R, Rea HH, Sutherland DC. Mortality from asthma: a new epidemic in New Zealand. Br Med f 1982;285:771-4.

2 Jackson RT, Mitchell EA. Trends in hospital admission rates and drug treatment of asthma in New Zealand. NZ Med f 1983;96:727-9.

3 Keating G, Mitchell EA, Jackson R, Beaglehole R, Rea $\mathrm{H}$. Trends in sales of drugs for asthma in New Zealand, Australia, and the United Kingdom, 1975-81. Br Med f 1984;289:348-51.

4 Wilson JD, Sutherland DC, Thomas AC. Has the change to beta-agonists combined with oral theophylline increased cases of fatal asthma? Lancet 1981;i:1235-7.

theophylline increased cases of fatal asthma? Lancet 1981;i:1235-7
Grant IWB. Asthma in New Zealand. Br Med f 1983;286:374-7.

6 British Thoracic Association. Death from asthma in two regions of England. Br Med $\mathcal{f}$ 1982:285:1251-5.

7 Sears MR, Rea HH, Beaglehole R, et al. Asthma mortality in New Zealand: a two year national study. NZ Med f 1985;98:271-5.
stis

8 Sears MR, Rea HH, de Boer G, et al. Accuracy of certification of deaths due to asthma: a national study. Am $\mathcal{J}$ Epidemiol (in press).

9 British Thoracic Association Research Committee. Accuracy of death certificates in bronchial asthma. Thorax 1984;39:505-9.

10 Sears MR, Rea HH, Fenwick J, et al. Seventy five deaths in asthmatics prescribed home nebulisers. Br Med $\mathcal{f}$ (in press).

11 World Health Organisation. International classification of diseases. 9th revision, 1975. Vol 1. Geneva: WHO, 1977.

12 Burney PGJ. Asthma mortality in England and Wales: evidence for a further increase, 1974-84. Lancet 1986;ii:323-6.

13 Ormerod LP, Stableforth DE. Asthma mortality in Birmingham 1975-7: 53 deaths. Br Med $\mathcal{J}$ 1980;280:687-90

14 Macdonald JB, Seaton A, Williams DA. Asthma deaths in Cardiff 1963-74; 90 deaths outside hospital. BrMed f 1976;i:1493-5.

15 Webb JR. Dose response of patients to oral corticosteroid treatment during exacerbations of asthma. Br Med F 1986;292:1045-7.
a

16 Thornley PE, Dawson KP. Asthma in New Zealand. Br Med J 1983;286:890-1.

17 Waite DA, Eyles EF, Tonkin SL, O'Donnell TV. Asthma prevalence in Tokelauan children in two environments. Clin Allergy 1980;10:71-5.

(Accepted 5 September 1986) 